\title{
SUMBER DAYA DALAM IMPLEMENTASI KEBIJAKAN PENDIDIKAN INKLUSI DI SDN BETET 1 KEDIRI
}

\author{
Nurin Kusnia \\ Prodi Pendidikan Agama Islam STAIN Kediri \\ nurinhusnia@gmail.com
}

\begin{abstract}
Good education, when able to accommodate all students, education that provides services without distinguishing physical, mental, intellectual, social, emotional, and so on, where all children can learn together, both in formal and non-formal schools which is adapted to the conditions and needs of each child. The purpose of this study is to describe the resources in the implementation of inclusive education in SDN Betet 1 Kediri. This type of research is a qualitative approach to the type of case study. Data collection uses observation, interview and documentation techniques. In implementing the implementation of the inclusion policy in SDN Betet 1 Kediri, there are several resource problems. The resources in the implementation of the inclusion have problems namely the lack of special assistant teachers (GPK), no psychology staff, therapists, and teams in particular, the unavailability of special spaces for handling children with special needs (ABK), classrooms for children with special needs (ABK) ) inadequate. The results of the research show that the resources in implementing the policy are still experiencing problems. Therefore, it is necessary to immediately allocate human and non-human resources that are not yet available so that the learning process can run optimally.
\end{abstract}

Keywords: inclusion, policy

\begin{abstract}
Abstrak: Pendidikan yang baik, ketika mampu mengakomodir seluruh peserta didik, pendidikan yang memberikan pelayanan tanpa membedakan kondisi fisik, mental, intelektual, sosial, emosi, dan sebagainya, di mana semua anak dapat belajar bersama-sama, baik di sekolah formal maupun non formal yang disesuaikan dengan kondisi dan kebutuhan masing-masing anak. Tujuan penelitian ini adalah untuk mendiskripsikan sumber daya dalam implementasi pendidikan inklusi di SDN Betet 1 Kediri. Jenis penelitian yang digunakan adalah dengan pendekatan kualitatif dengan jenis studi kasus. Pengumpulan data menggunakan teknik observasi, wawancara dan dokumentasi. Dalam pelaksanaan implementasi kebijakan penyelenggaraan inklusi di SDN Betet 1 Kediri terdapat beberapa masalah sumber daya. Sumber daya dalam implementasi penyelenggaraan inklusi ini memiliki masalah yaitu mengenai kuranganya guru pendamping khusus (GPK), tidak ada tenaga psikologi, terapis, dan tim khususnya, tidak tersedianya ruang khusus penanganan anak berkebutuhan khusus (ABK), ruang kelas untuk anak berkebutuhan khusus (ABK) yang kurang memadai. Hasi penelitia menunjukan bahwa sumber daya dalam implementasi kebijakan masih mengalami kendala. Oleh karena itu, perlu segera dialokasikan sumber daya manusia dan non manusia yang belum tersedia agar proses pembelajaran dapat berjalan secara maksimal.
\end{abstract}

Kata kunci: inklusi, kebijakan

Pendidikan inklusi merupakan suatu pendidikan dimana anak-anak bekebutuhan khusus diintregasikan ke sekolah-sekolah umum dengan menggunakan seoptimal mungkin seluruh fasilitas yang ada serta dukungan dari lingkunagan sekolah. Pelaksanaan pendidikan inklusi dilandasi keyakinan bahwa semua orang adalah bagian yang berharga dalam kebersamaan masyarakat, apa pun perbedaan mereka. (Kosasih, 2012)

Pendidikan yang memberikan layanan terhadap semua tanpa memandang kondisi fisik, mental, intelektual, sosial, emosi, ekonomis, jenis kelamin, suku 
budaya, tempat tinggal, bahasa dan sebagainya, di mana semua anak dapat belajar bersama-sama, baik di sekolah formal maupun non formal yang berada di dekat tempat tinggalnya yang disesuaikan dengan kondisi dan kebutuhan masingmasing anak. (Sukinah, 2010)

Menurut Suparno, pendidikan inklusif adalah suatu sistem layanan pendidikan untuk anak-anak berkebutuhan khusus di kelas normal bersama-sama dengan teman sebayanya. Jadi pendidikan inklusif adalah sistem penyelenggaraan pendidikan yang memberikan kesempatan kepada semua peserta didik yang memiliki kelainan dan memiliki potensi kecerdasan dan/atau bakat istimewa untuk mengikuti pendidikan atau pembelajaran dalam satu lingkungan pendidikan secara bersamasama dengan peserta didik pada umumnya.

Depdiknas menegaskan bahwa pendidikan inklusif didefinisikan sebagai sistem layanan pendidikan yang mengikutsertakan anak berkebutuhan khusus belajar bersama dengan anak sebayanya di sekolah reguler yang terdekat dengan tempat tinggalnya. (Depdiknas, 2007) Dengan demikian penyelenggaraan pendidikan inklusif menuntut pihak sekolah untuk melakukan penyesuaian baik dari segi kurikulum, sarana prasarana pendidikan, maupun sistem pembelajaran yang disesuaikan dengan kebutuhan dan karakteristik peserta didik (siswa).

Acuan formal yang sudah ada di Indonesia adalah Keputusan Menteri Pendidikan dan Kebudayaan No. 002/U/1968, tentang Pendidikan Terpadu bagi anak cacat, Bab I, pasal 1 yang menyatakan bahwa (a) Pendidikan Terpadu ialah model penyelenggaraan program pendidikan bagi anak cacat yang diselenggarakan bersama anak normal di lembaga pendidikan umum dengan menggunakan Kurikulum yang berlaku di lembaga pendidikan yang bersangkutan. Sedangkan dalam Rancangan Peraturan Pemerintah Tahun 2003, tentang pendidikan khusus dan pendidikan layanan khusus (RPP-PK dan PLK) Bab I, Pasal 1 ayat (7) dinyatakan Pendidikan Inklusi adalah pendidikan reguler yang disesuaikan dengan kebutuhan peserta didik.

Peraturan Menteri Pendidikan Dan Kebudayaan Republik Indonesia No. 0491/u/1992 Tanggal 30 November 1992 Pada Bab X1 Tentang Penilaian Dan Bab X11 Tentang Bimbingan Dan Rehabilitas. Untuk itu uraian berikut akan difokuskan pada rehabilitas yang ketentuannya menyatakan bahwa: rehabilitas diberikan oleh ahli terapi fisik, ahli terapi bicara, dokter umum, dokter spesialis, psikologi, perawat, dan pekerja sosial. (Nawawi, Hadari, \& Hartini, 1994)

Kemudian berdasarkan Peraturan Menteri Pendidikan Nasional RI Nomor 7 Tahun 2009 tentang Pendidikan Inklusif, Pemerintah Provinsi Jawa Timur telah menyikapi dengan mengeluarkan kebijakan, melalui Peraturan Gubernur Jawa Timur Nomor 6 Tahun 2011 tentang Penyelenggaraan Pendidikan Inklusif sudah dilaksanakan di Provinsi Jawa Timur. (Sudarto, 2016)

Dalam pendidikan inklusif terdapat beberapa prinsip yang berkaitan langsung dengan jaminan akses dan peluang bagi semua anak Indonesia untuk memperoleh pendidikan tanpa memandang latar belakang kehidupan mereka. (1) Pendidikan inklusif membuka kesempatan kepada semua jenis siswa. (2) Pendidikan inklusif menghindari semua aspek negatif labeling. (3) Pendidikan inklusif selalu melakukan Check dan Balances.(Ilahi, 2013)

Dalam kegiatan pembelajaran pada sekolah inklusif seorang guru juga harus memperhatikan prinsip-prinsip berikut: (1) Prinsip motivasi, guru harus senantiasa memberikan motivasi kepada siswa agar tetap memiliki gairah dan semangat yang tinggi dalam mengikuti kegiatan belajar mengajar, (2) Prinsip latar/konteks, guru perlu mengenal siswa secara mendalam, (3) Prinsip keterarahan, setiap akan melakukan kegiatan pembelajar guru harus merumuskan tujuan secara jelas, menyiapkan bahan dan alat yang sesuai, serta mengembangkan strategi pembelajaran yang tepat, (4) Prinsip hubungan sosial, dalam kegiatan belajar mengajar, guru perlu mengembangkan strategi pembelajaran yang mampu mengoptimalkan interaksi antara guru 
dengan siswa, siswa dengan siswa, guru dengan siswa dan lingkungan serta interaksi banyak arah, (5) Prinsip belajar sambil bekerja, guru harus banyak memberikan kesempatan kepada anak untuk melakukan praktek atau percobaan, atau merumuskan sesuatu melalui pengamatan, penelitian atau sebagainya, (6) Prinsip individulisasi, guru perlu mengenal kemampuan awal dan karakteristik setiap anak secara mendalam, bagi dari segi kemampuan maupun ketidakmampuannya dalam menyerap materi pembelajaran, kecepatan maupun kelambatannya dalam belajar, dan perilakunya, sehingga kegiatan pembelajaran masing-masing anak mendapatkan perhatian dan perlakuan yang sesuai, (7) Prinsip menemukan, guru perlu mengembangkan strategi pembelajaran yang mampu memancing siswa untuk terlibat secara aktif, baik fisik, mental, sosial, dan emosional, (8) Prinsip pemecahan masalah, guru hendaknya sering mengajukan berbagai persoalan atau problem yang ada di lingkungan sekitar, dan anak dilatih untuk merumuskan, mencari data, menganalisis dan memecahkannya sesuai dengan kemampuannya. (Indianto, 2013)

Guru harus mampu mengetahui potensi individu setiap siswa dan pengalaman hidup, untuk menentukan metode serta variasi media pembelajaran.(Mara \& Mara, 2012)

Dalam pelaksanaannya pendidikan inklusi di indonesia diselenggarakan dengan tujuan sebagai berikut: (Indianto R. 2013) (1) Memberikan kesempatan yang seluas-luasnya kepada semua anak (termasuk anak berkebutuhan khusus) untuk mendapatkan pendidikan yang layak sesuai dengan kebutuhan dan kemampuannya. (1) Membantu mempercepat program wajib belajar pendidikan dasar. (3) Membantu meningkatkan mutu pendidikan dasar dan menengah dengan menekan angka tinggal kelas dan putus sekolah. (4) Menciptakan sistem pendidikan yang menghargai keanekaragaman, tidak diskriminatif, serta ramah terhadap pembelajaran. Memenuhi amanat Undang-Undang Dasar 1945
Pendidikan inklusi memiliki peranan penting untuk mengintegrasikan penderita disabilitas agar mampu diterima dan dapat bersosialisasi dengan masyarakat (Borodkina, 2014). Oleh karena itu perlu dikembangkan system pendidikan dan kurikulum yang tepat untuk merespon seluruh kebutuhan, karakteristik, dan perbedaan individu seluruh siswa inklusi di sekolah.(Unianu, 2012)

Pendidikan inklusi membutuhkan peralatan yang lengkap, guru yang berwawasan dan kompeten yang mampu mensuport siswa berkebutuhan khusus untuk mempersiapkan mereka menjadi warga Negara yang kapabel.(Marimuthu \& Cheong, 2015). Kenyataan di lapangan menunjukkan bahwa pendidikan inklusi membutuhkan proses yang panjang, kerja yang sangat keras dengan membutuhkan banyak energy serta motivasi. (Atanasoska, Cvetkova, lliev, \& Andonovska-, 2015)

\section{METODE}

Jenis penelitian ini adalah penelitian dengan menggunakan pendekatan kualitatif dengan jenis studi kasus. Penelitian ini mengambil fokus teori George C. Edward III (Fryde, 2018) yang di pengaruhi oleh empat variabel yaitu, struktur birokasi, sumber daya, disposisi, dan komunikasi.

Pengumpulan data menggunakan sumber data primer yang diperoleh dari sumber data aslinya melalui wawancara narasumber yang tepat dan dijadikan responden dalam penelitian.(Sugiyono, 2012) Sumber data yang digunakan yaitu, Kepala Sekolah dan 3 Guru Pendamping Khusus (GPK).

Teknik Pengumpulan Data yang menggunakan wawancara, observasi, dan dokumentasi.(Cresswell, 2010)

\section{HASIL DAN PEMBAHASAN}

1. Kebijakan Pendidikan Inklusi

Dalam Peraturan Menteri Pendidikan Dan Kebudayaan Republik Indonesia No. 0491/u/1992 Tanggal 30 November 1992 Pada Bab X1 Tentang Penilaian Dan Bab X11 Tentang Bimbingan Dan Reahabilitas. Untuk itu uraian berikut 
akan difokuskan pada rehabilitas yang ketentuanya menyatakan bahwa: rehabilitasi diberikan oleh ahli terapi fisik, ahli terapi bicara, dokter umum, dokter spesialis, psikologi, perawat, dan pekerja sosial. (Nawawi et al., 1994)

2. Sumber Daya Dalam Implementasi Kebijakan Pendidikan Inklusi

Dalam teori implemetasi kebijakan menurut George Edward III (Mulyasa, 2004)terdapat variabel sumber daya, sumber daya merupakan hal penting dalam implementasi kebijakan yang baik, dalam pelaksanaan sumber daya ini terdapat 4 indikator yang perlu diperhatikan yaitu: Staf, Anggaran, Informasi, dan Fasilitas.

Pertama, sumber daya mausia (Staf) merupakan Sumber daya utama dalam implementasi kebijakan. Kegagalan yang sering terjadi dalam implementasi kebijakan, salah-satunya disebabkan oleh staf/pegawai yang tidak cukup memadai, mencukupi, ataupun tidak kompeten dalam bidangnya. (Kantavong, Nethanomsak, \& luangungkool, 2013) Penambahan jumlah staf dan implementor saja tidak cukup menyelesaikan persoalan implementasi kebijakan, tetapi diperlukan sebuah kecukupan staf dengan keahlian dan kemampuan yang diperlukan (Kompeten dan Kapabel) dalam mengimplementasikan kebijakan. Kualtias pendidikan pertama kali tergantung kepada kualitas dari guru yang merencanakan, mengimplementasikan serta mengevaluasi kegiatan pembelajaran. (Maria, 2013). Pengalaman dari proses belajar akan membantu siswa dalam bersikap serta menghargai orang dengan kebutuhan khusus. (Kantavong et al., 2013)

Hasil Penelitian menunjukan bahwa sumber daya manusia dalam implementasi kebijakan pendidikan inklusi di SDN Betet 1 Kediri masih belum berjalan secara maksimal karena masih ditemukan beberapa permasalahan sumber daya manusia yaitu: pertama, jumlah peserta didik anak berkebutuhan khusus 63 siswa tidak sebanding dengan jumlah guru pendamping khusus yang belatar belakan pendididkan luar biasa (PLB) hanya berjumlah satu orang. Kedua; tidak adanya tenaga psikologi, terapis, doktor dan tim khusus sehingga ada guru yang merangkap pekerjaan yang tidak sesuai dengan bidang pendidikan dan keahlianya. Guru membutuhkan pelatihan khusus pendidikan inklusif mengingat tantangan system pendidikan di dunia yang semakin mendesak dan berkembang. (GonzálezGil et al., 2013)

Kedua, Anggaran (Budgetary) Dalam implementasi kebijakan, anggaran berkaitan dengan kecukupan modal atau investasi atas suatu program atau kebijakan untuk menjamin terlaksananya kebijakan, sebab tanpa dukungan anggaran yang memadahi, kebijakan tidak akan berjalan dengan efektif dalam mencapai tujuan dan sasaran.

Hasil penelitian menunjukan bahwa sumber daya non-manusia yang berupa Anggaran dalam implementasi kebijakan pendidikan inklusi di SDN Betet 1 Kediri sudah mulai berjalan, pada akhir tahun 2016 pemerintah memberikan dana alokasi khusus sebesar 240.000.000,00 yang merupakan dana APBN dan APBD.

Ketiga, Informasi (Information) Dalam implementasi kebijakan, informasi mempunyai dua bentuk yaitu: pertama, informasi yang berhubungan dengan cara melaksanakan kebijakan. Kedua, informasi mengenai data kepatuhan dari para pelaksana terhadap peraturan dan regulasi pemerintah yang telah ditetapkan.

Hasil penelitian menunjukan bahwa Informasi dalam implementasi kebijakan pendidikan inklusi di SDN Betet 1 Kediri. Pertama, yang berhubungan dengan cara pelaksanaanaya sudah sesuai dengan prinsip dan tujuan adanya pendidikan inklusi akan tetapi masih belum berjalan sesuai dengan kebijakan pemerintah mengenai bimbingan dan rehabilitas yang ada dalam pendidikan inklusi. Kedua, dalam pelaksanaan peraturan dan regulasi yang telah ditetapkan pemerintah masih belum berjalan secara maksimal, karena 
kurangnya sumber daya manusia, fasilitas dan dana yang perlu dialokasikan.

Keempat, Fasilitas atau sarana dan prasarana merupakan salah satu faktor yang berpengaruh dalam implementasi kebijakan. Pengadaan fasilitas yang layak, seperti gedung, tanah dan peralatan perkantoran akan menunjang dalam keberhasilan implementasi suatu program atau kebijakan.(Asiabaka, 2008)

Hasil penelitian menunjukan bahwa sumber daya non-manusia yang berupa fasilitas dalam implementasi pendidikan inklusi di SDN Betet 1 kediri sangat kurang memadai karena ditemukan beberapa kendala mengenai Ruang Khusus untuk ABK masih belum ada, dan pembelajaran ABK pun harus berada di UKS untuk anak kelas bawah, sedangkan untuk anak kelas atas ruangannya menempati ruang anak yang ada jam olahraga, mengenai ruang anak $A B K$ dulu di gabung dengan anak reguler, akan tetapi seiring berjalannya waktu yang dirasa kurang efektif, akhirnya anak ABK dipisah dengan anak reguler dan di tempatkan di UKS, sedangkan ruang terapi untuk anak ABK diletakkan di perpustakaan.

\section{KESIMPULAN}

Sumber daya yang dialokasikan dalam pelaksanaan Peraturan Gubernur Jawa Timur Nomor 6 Tahun 2011 tentang Penyelenggaraan Pendidikan Inklusif yaitu sumber daya manusia dan non-manusia. Dalam pelaksanaan sumber daya dalam implementasi program pendidikan inklusif SDN Betet 1 Kediri mengalami kendala dari segi sumber daya manusia dan nonmanusia, yaitu kurangnya guru pendidik khusus, tidak tersedianya tenaga terapis, serta tidak tersedianya tenaga tim khusus. Oleh karena itu, perlu segera dialokasikan sumber daya manusia dan non-manusia yang belum tersedia agar proses pembelajaran dapat berjalan secara maksimal.

Sumber daya non-manusia dibagi menjadi dua yaitu dana dan peralatan. Sumber dana yang digunakan dalam pelaksanaan program pendidikan inklusi yaitu dari dana APBN dan APBD. Kemudian Peralatan yang dibutuhkan peserta didik berkebutuhan khusus belum terpenuhi secara maksimal.

\section{DAFTAR RUJUKAN}

Asiabaka, I. P. (2008). Facilities Management in Schools. New York Science Journal, 1(2), 10-21.

Atanasoska, T., Cvetkova, B., lliev, D., \& Andonovska-, D. (2015). Inclusive Practice in $\mathrm{R}$. Macedonia at the Beginning of Efforts. Procedia - Social and Behavioral Sciences, 191, 13281331.

https://doi.org/10.1016/j.sbspro.2015. 04.585

Borodkina, O. (2014). Problems of the Inclusive Professional Education in Russia. Procedia - Social and Behavioral Sciences, 140, 542-546. https://doi.org/10.1016/j.sbspro.2014. 04.467

Cresswell, J. W. (2010). Research design (Pendekatan kualitatif, kuantitatif dan mixed). Yogyakarta: Pustaka Pelajar.

Fryde, E. B. (2018). Financial Resources of Edward III in the Netherlands, 133740 (2nd part ). 40, 1142-1216.

González-Gil, F., Martín-Pastor, E., Flores, N., Jenaro, C., Poy, R., \& GómezVela, M. (2013). Teaching, Learning and Inclusive Education: The Challenge of Teachers' Training for Inclusion. Procedia - Social and Behavioral Sciences, 93, 783-788. https://doi.org/10.1016/j.sbspro.2013. 09.279

Ilahi, M. T. (2013). Pendidikan Inklusif: Konsep dan aplikasi. Yogyakarta: Ar Ruzz Media.

Indianto, R. (2013). Sekolah Inklusi: Implementasi Pendidikan Inklusif Surakarta.

Kantavong, P., Nethanomsak, T., \& luangungkool, N. (2013). Inclusive Education in Thailand after 1999 National Education Act: A Review of a Pre-Service Teacher Education System. Procedia - Social and 
Behavioral Sciences, 69(Iceepsy), 1043-1051.

https://doi.org/10.1016/j.sbspro.2012. 12.031

Kosasih, E. (2012). Cara bijak memahami anak berkebutuhan khusus. Bandung: Yrama Widya Nawawi.

Mara, D., \& Mara, E.-L. (2012). Curriculum Adaption in Inclusive Education. Procedia - Social and Behavioral Sciences, 46(Bobitt 1924), 40044009.

https://doi.org/10.1016/j.sbspro.2012. 06.187

Maria, U. E. (2013). Teachers' Perception, Knowledge and Behaviour in Inclusive Education. Procedia - Social and Behavioral Sciences, 84, 1237-1241. https://doi.org/10.1016/j.sbspro.2013. 06.736

Marimuthu, S., \& Cheong, L. S. (2015). Inclusive Education for Social Transformation. Procedia - Social and Behavioral Sciences, 172, 317-322. https://doi.org/10.1016/j.sbspro.2015. 01.370
Mulyasa, E. (2004). Manajemen Berbasis Sekolah, Konsep, Strategi dan Implementasi. Bandung: Rosdakarya.

Nawawi, Hadari, \& Hartini, M. (1994). Kebijakan Pendidikan Di Indonesia Ditinjau Dari Sudut Hukum. Yogyakarta: Gajah Madha Univesity Press.

Sudarto, Z. (2016). Implementasi Kebijakan Penyelenggaraan Pendidikan Inklusif. Jurnal Pendidikan, 1(1).

Sugiyono. (2012). Metode Penelitian Kuantitatif Kualitatifdan R\&D. Bandung: Alfabeta.

Sukinah. (2010). Manajemen Strategik Implementasi Pendidikan Inklusif. Jurnal Pendidikan Khusus, 7(2).

Unianu, E. M. (2012). Teachers' attitudes towards inclusive education. Procedia - Social and Behavioral Sciences, 33, 900-904. https://doi.org/10.1016/j.sbspro.2012. 01.252 